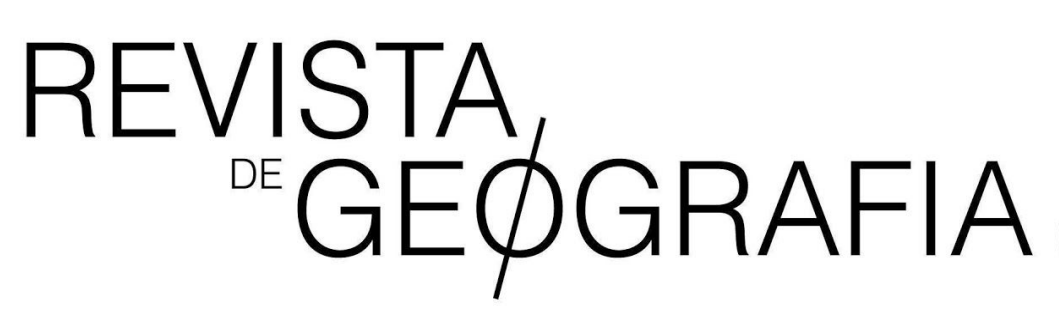

PPGEO
Programa de Pós-Graduação
em Geografia ufjf

\title{
A VULNERABILIDADE DO HAITI FRENTE Á VARIABILIDADE CLIMÁTICA
}

THE VULNERABILITY OF HAITI IN FRONT OF CLIMATE VARIABILITY

Ralph Charles

Universidade Estadual de Campinas - UNICAMP Cidade Universitária Zeferino Vaz - Barão Geraldo, Campinas - SP. CEP: 13083-970

E-mail: cralph001@yahoo.fr

Regina Célia De Oliveira

Universidade Estadual de Campinas - UNICAMP

Cidade Universitária Zeferino Vaz - Barão Geraldo, Campinas - SP. CEP: 13083-970

E-mail: reginacoliveira@ige.unicamp.br

Priscila Pereira Coltri

Universidade Estadual de Campinas - UNICAMP Cidade Universitária Zeferino Vaz - Barão Geraldo, Campinas - SP. CEP: 13083-970 E-mail: priscilapereira.coltri@gmail.com

Rafael Vinicius São José

Universidade Estadual de Campinas - UNICAMP Cidade Universitária Zeferino Vaz - Barão Geraldo, Campinas - SP. CEP: 13083-970 E-mail: rafauniversitario16@hotmail.com 


\title{
Resumo
}

O uso inapropriado dos recursos naturais resultou em algumas mudanças no conjunto dos elementos que compõem os ecossistemas e torna a população vulnerável a cenários tais como incêndios florestais, secas, furacões, tempestades tropicais, nevascas, enchentes e outros. No Haiti, historicamente, o país enfrenta problemas climáticos devido sua situação geográfica e o uso e ocupação inadequado do solo. Estes fatores podem contribuir para aumentar a sensibilidade local em relação a ocorrências de fenômenos naturais como terremoto, furacão, secas e enchentes. Desta maneira, esta pesquisa objetivou analisar a vulnerabilidade da República do Haiti frente à eventos climáticos naturais durante as últimas décadas. Os resultados mais relevantes indicam que os anos de 2014 e 2015 foram marcados por uma longa seca que afetou quase todo o país, danificou severamente os meios de subsistência e a segurança alimentar do país.

Palavras-chave: Climatologia, Riscos ambientais, Fragilidade, Haiti.

\begin{abstract}
Inappropriate use of natural resources has resulted in some changes in the set of ecosystem elements and makes the population vulnerable to scenarios such as forest fires, droughts, hurricanes, tropical storms, snowfalls, floods and others. In Haiti, historically, the country faces climate problems due to its geographical situation and inadequate land use and occupation. These factors may contribute to increase local sensitivity to occurrences of natural phenomena such as earthquake, hurricane, droughts and floods. Thus, this research aimed to analyze the vulnerability of the republic of Haiti to natural climate events during the last decades. The most relevant results indicate that the years 2014 and 2015 were marked by a long drought that affected almost the entire country, severely damaged the country's livelihoods and food security.
\end{abstract}

Key words: Climatology, Environmental risks, Fragility, Haiti. 


\section{Introdução}

Os estudos sobre vulnerabilidade sócio-ambiental de sistemas têm crescido nos últimos anos, referindo-se as categorias de eventos meteorológicos que tem acontecido no mundo. A expansão habitacional dos grandes centros urbanos, sem planejamento, além do escasso de conhecimento ecológico dos governos e da população, aliados à falta de políticas públicas para o setor, têm colocado em risco, as áreas de preservação permanentes inseridas no meio urbano que consequentemente aumenta a ocorrência de desastres associados ao uso e ocupação inadequados de encostas e topos de morro. Essas regiões estão mais propensas ao desmatamento, deposição de resíduos, assoreamento dos rios e poluição das águas (Banque Mondial, 2019).

Destacando a contribuição do pensamento sistêmico para a análise e espacialização da vulnerabilidade, faz-se necessário uma breve discussão sobre o que se entende como vulnerabilidade, sobre sua aplicação em regiões degradadas, bem como acerca da metodologia necessária à sua aplicação. É importante destacar que o conceito de vulnerabilidade foi utilizado primeiro na engenharia em referência aos níveis de resistência de materiais, desenhos e valores de edificações frente a terremotos, ação do vento e da água. De acordo com CEPAL (2010), a vulnerabilidade é o nível ou grau em que um sujeito ou elemento exposto pode ser afetado quando dispor a uma ameaça. Porém, foi a partir da década de 80 , que o conceito passou a ser utilizado, a princípio, em relação ao impacto de desastres, e posteriormente, na localização desses impactos, fazendo menção a fenômenos e eventos naturais e/ou antrópicos (MAZZER, 2007).

De acordo com Villa e McLeod (2002) a construção de um método de avaliação da vulnerabilidade ambiental requer três passos necessários: definição do conceito de vulnerabilidade, escolha do sistema a ser avaliado e, por fim escolha e organização dos indicadores ambientais. Assim, a pesquisa afirma que a necessidade de definir o conceito de vulnerabilidade advém da existência de diversos estudos sobre o tema, com diferentes abordagens de análise. O estudo da vulnerabilidade também requer a delimitação do sistema ambiental em estudo, assim como a identificação dos seus elementos constituintes. A escolha dos indicadores deve estar atrelada ao conceito de vulnerabilidade adotado e ao objetivo da análise (CEPAL, 2010).

As secas causadas pelo fenômeno climático El Niño e pela agitação oceanica aumentaram para 37, em comparação com 34 em março do 2015, o número de países que atualmente precisam de ajuda alimentar externa, segundo um novo relatório da FAO. A última edição das Perspectivas de Culturas e Situação Alimentar, publicada em 2 de junho 2015, 
adiciona Papua Nova Guiné, Haiti e Nigéria à lista de países que precisam de assistência externa para alimentar suas populações ou comunidades (LE NOUVELLISTE, 2016).

Segundo um relatório da Oxfam (confederação de 19 organizações e mais de 3000 parceiros, que atua em mais de 90 países na busca de soluções para o problema da probreza, desigualdade e injustiça por meio de campanhas, programas de desenvolvimento e ações paliativas) em março de 2018, as mudanças climáticas já são evidentes no Haiti, com temperaturas médias que aumentaram e continuarão a aumentar nos próximos anos; estações que se tornam cada vez mais variáveis com uma estação chuvosa que começa três meses mais tarde que o padrão e é composta por chuvas muito fortes e estações secas que estão se tornando mais severas.

De acordo com a mesma pesquisa uma das principais consequências das mudanças climáticas no Haiti será a deterioração da insegurança nutricional das populações e, portanto, o aumento da subnutrição, pois mais de um quinto da população vive da agricultura e é o setor a economia mais vulnerável. O impacto das mudanças climáticas no sistema alimentar será sentido em diferentes níveis como danos ambientais, degradação socioeconómico, declínio na produção de alimentos.

O Haiti não possui sistemas adequados para coletar dados sobre clima, solo e culturas agrícolas, segundo a afirmação do Ministério do Meio Ambiente deste país (MDE, 2006). De acordo com a mesma pesquisa, a atual rede de estações meteorológicas é, por exemplo, muito subdesenvolvida. Os esforços recentes do governo para implementar, com apoio de doadores, um censo agrícola preexistente são um passo importante para a solução dos problemas. Melhorar a coleta de dados é crucial para criar resiliência às mudanças climáticas (PNUE, 2016).

O relatório do Ministério do meio Ambiente do Haiti em colaboração ao Programa das Nações Unidas para o Desenvolvimento (MDE/ MNUD, 2015) afirma que o clima no Haiti mudou nas últimas quatro décadas, as temperaturas médias aumentaram e a estação das chuvas começa agora três meses depois do que o habitual. As projeções mais recentes indicam que as temperaturas médias continuarão a aumentar ao longo do século XXI. A variabilidade das chuvas também está aumentando, produzindo a secas mais severas na estação seca e chuvas intensas na estação chuvosa.

De acordo MDE/ MNUD (2015) a elevação do nível do mar e a maior frequência de tempestades também estão previstas a curto prazo. As áreas costeiras estão expostas ao aumento da intrusão de água salgada que impede os agricultores de cultivar suas terras. Esses fatores agravarão os problemas de inundações e erosão costeira relacionados à 
tempestades e furacões. Na ausência de esforços significativos de adaptação, esses mecanismos afetarão severamente os recursos hídricos, solos, agricultura e florestas.

As inundações são consideradas um dos maiores problemas em quase todos os trintas (30) principais rios do país, devido às intensas chuvas sazonais causando sedimentação dos leitos dos rios. As inundações levam terras aráveis e as depositam nos leitos dos rios. Particularmente vulnerável a desastres naturais causados por furacões e tempestades tropicais, o Haiti é altamente vulnerável a riscos climáticos. A mudança climática se reflete tanto no aumento da temperatura média da superfície global quanto no aumento da frequência de temperaturas extremas (MDE, MNUD, 2015).

Se este último parâmetro induz em reiterados fenômenos de secas, é sobretudo o aumento da temperatura média que terá mais consequências no Haiti, sendo que, a atmosfera se torna mais úmida devido ao aumento da evaporação, os ciclones se intensificam e são mais difícil de prever. De acordo com a pesquisa, isso aumenta drasticamente o dano potencial, tendo como resultado, a economia haitiana se tornará ainda mais vulnerável a eventos aleatórios e extremos relacionados às mudanças climáticas.

\section{Materiais e Métodos}

A pesquisa inciou-se com o levantamento cartográfico e o estudo dos fenômenos climáticos ocorridos no pais durante estas últimas décadas, a fim de subsidiar o estudo dos fenômenos climáticos no Haiti. Em segundo lugar, foram realizados trabalhos de levantamento bibliográfico, composto por revisão e análise de artigos nacionais e internacionais, teses, dissertações que trata prioritariamente dos temas de problemas socio-ambientais do território haitiano. Além disso, analisou-se artigos dissertações e teses realizadas na área de estudo sobre à caracterização natural (geologia, geomorfologia, hidrográfica, vegetação, hipsometria, pluviometria) e antrópica (economia e história) na região do Caríbe e mais especificamente no Haiti.

Em terceiro lugar, consultou-se, também, fontes, como, por exemplo, a Organização das Nações Unidas (ONU) e AlterPresse, periódico de grande circulação no país, para descrever os danos registrados no Haiti após a ocorrência de catástrofes naturais (furacões, inundações e terremotos). Do ponto de vista cartográfico, foi elaborado o mapa de localização da área de estudo, na escala 1:100.000, utilizando imagens orbitais, disponibilizadas no Google Earth, manipulada no soltware Arc Gis 10.1.

Para diagnosticar os impactos provocados pelos eventos extremos na área de estudo, utilizou-se a pesquisa exploratória, definida por Marconi e Lakatos (2001) como estudos que 
têm por objetivo a formulação de um problema com a finalidade de aumentar a familiaridade dos pesquisadores com um ambiente, fato ou fenômeno, para realização de pesquisas futuras mais aprofundadas no âmbito de propor soluções.

\section{Resultados e discussões}

\subsection{Localização e caracterização do Haiti}

De acordo com l'Institut Haitien de Statistique e d'Informatique (IHSI, 2002), a república do Haiti ocupa uma área de $27.750 \mathrm{~km}^{2}$ e um o terço ocidental da ilha de Hispaniola (76.115 $\mathrm{km}^{2}$ ) que compartilha com a República Dominicana. O Haiti está localizado entre $18^{\circ}$ e $20^{\circ} 6^{\prime}$ de latitude norte e entre $71^{\circ} 20^{\prime}$ e $74^{\circ} 30^{\prime}$ de longitude oeste. Limitado a norte pelo Oceano Atlântico, a oeste e sul pelo mar do Caribe, a leste pela República Dominicana (RD). A costa haitiana se estende por $1535 \mathrm{~km}$, com uma plataforma continental relativamente estreita de $5000 \mathrm{~km}^{2}$. O território haitiano inclui também cinco ilhas satélites: La Gonave $\left(670 \mathrm{~km}^{2}\right)$, La Tortue $\left(180 \mathrm{~km}^{2}\right)$, lle-à-vache $\left(52 \mathrm{~km}^{2}\right)$, Cayemites $\left(45 \mathrm{~km}^{2}\right)$ e La Navase $\left(7 \mathrm{~km}^{2}\right)$. A localização geográfica do Haiti encontra-se na figura 1.

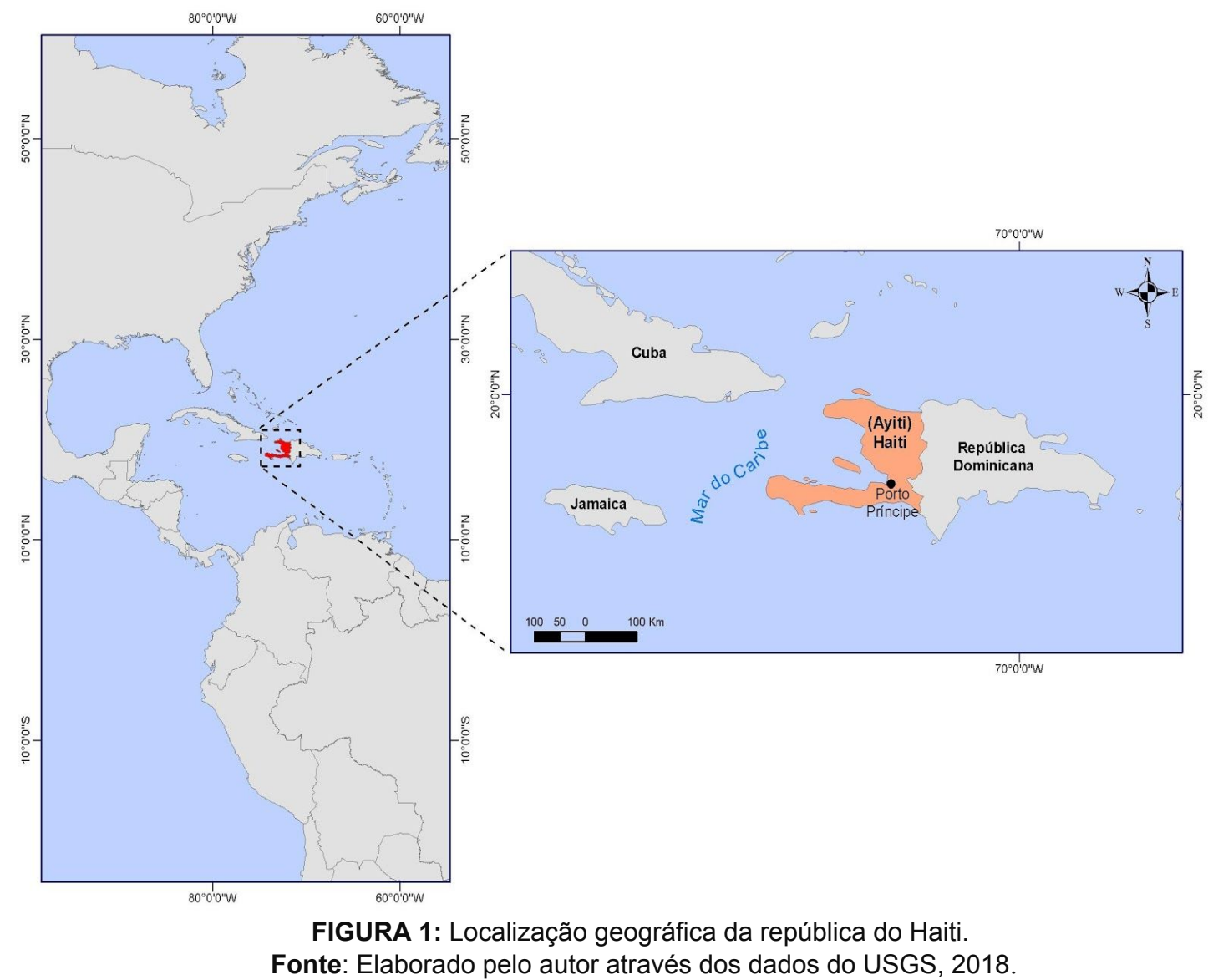

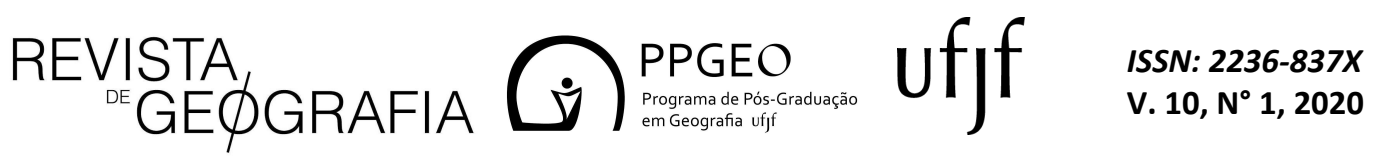


O Haiti possui um clima tropical. A temperatura média anual é de $27{ }^{\circ} \mathrm{C}$, porém, na parte montanhosa, esta pode ser menor que $20^{\circ} \mathrm{C}$, podendo atingir valores menores que 10 ${ }^{\circ} \mathrm{C}$ na região do pico La Selle, no inverno, particularmente entre dezembro e janeiro (JEUNE, 2015). A estação chuvosa ocorre entre os meses de maio a julho e a estação de furacões ocorre entre os meses de junho a novembro e no inverno a pluviosidade é menor que no verão (PNUD, 2019). Segundo a Köppen e Geiger o clima é classificado como Aw. $26.6{ }^{\circ} \mathrm{C}$ é a temperatura média anual de pluviosidade é de $964 \mathrm{~mm}$. Para Jeune (2015), a região apresenta dois tipos de clima devido à variação da altitude. O tipo tropical "Aw" caracteriza as planícies e colinas que têm uma baixa variação de temperatura durante o ano; enquanto nas regiões mais altas encontra-se o tipo "Cwb", ou seja, clima tropical de altitude com inverno seco e verão quente. A figura 2 apresenta a variação de precipitação (en azul) e temperatura anual na área de estudo (em vermelho).

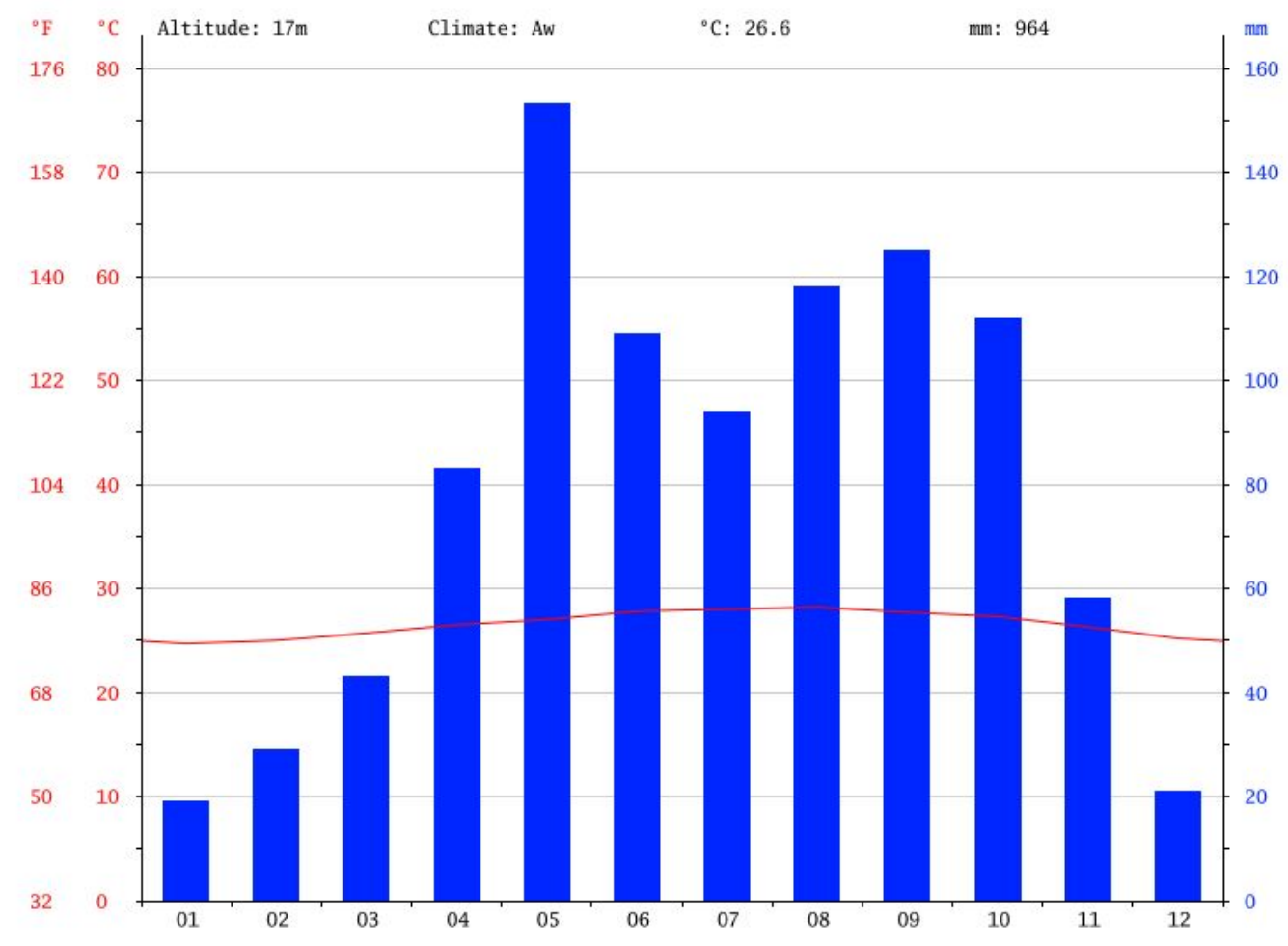

FIGURA 2: Gráfico climático no Haiti.

Fonte: Climate-Data. ORG, disponível em:

https://fr.climate-data.org/amerique-du-nord/haiti/departement-de-I-ouest/arcahaie-29873/\#climate-graph . Acessado em 12 de Julho de 2019.

Como podemos observar na figura 2, o mês mais seco (janeiro) tem uma diferença média de precipitação de $134 \mathrm{~mm}$ em relação ao mês mais chuvoso (maio). A diferença de temperatura dos meses entre a temperatura mais baixa e a mais alta é de $3,5{ }^{\circ} \mathrm{C}$. Com 
temperatura média de $28.2^{\circ} \mathrm{C}$, agosto é o mês mais quente do ano e Janeiro é o mês mais frio do ano (figura 3). A temperatura média anual é de $24,7^{\circ} \mathrm{C}$.

\begin{tabular}{|l|c|c|c|c|c|c|c|c|c|c|c|c|}
\hline & Jan & Fev & Mar & Abr & Maio & Jun & Jul & Ag & Sep & Out & Nov & Dez \\
\hline Tempereatura média $\left({ }^{\circ} \mathrm{C}\right)$ & 24.7 & 25 & 25.7 & 26.5 & 27 & $\begin{array}{c}27 . \\
8\end{array}$ & 28 & 28.2 & 27.7 & 27.3 & 26.3 & 25.2 \\
\hline Tempatura min midia $\left({ }^{\circ} \mathrm{C}\right)$ & 18.6 & 18.8 & 19.7 & 21 & 21.8 & $\begin{array}{c}22 . \\
3\end{array}$ & 22.4 & 22.6 & 22.3 & 22.1 & 21.1 & 19.6 \\
\hline Temperatura min $\left({ }^{\circ} \mathrm{C}\right)$ & 30.8 & 31.3 & 31.8 & 32 & 32.3 & $\begin{array}{c}33 . \\
3\end{array}$ & 33.7 & 33.8 & 33.2 & 32.6 & 31.5 & 30.8 \\
\hline Precipitação $(\mathrm{mm})$ & 19 & 29 & 43 & 83 & 153 & 109 & 94 & 118 & 125 & 112 & 58 & 21 \\
\hline
\end{tabular}

FIGURA 3: Temperatura média, mínima, máxima e precipitação média anual no Haiti. Fonte: Adaptação do Climate-Data. ORG, disponível em,

https://fr.climate-data.org/amerique-du-nord/haiti/departement-de-l-ouest/arcahaie-29873/\#climate-graph. Acessado em 12 de Julho de 2019.

De acordo com Jeune (2015), a distribuição média anual da precipitação apresenta os meses de maio e outubro como os mais chuvosos; e os mais secos variam de dezembro a fevereiro. Por outro lado, a umidade relativa média anual do ar, segundo Woodring et al (1924), é de $80 \%$ no verão e de $78 \%$ no inverno. As oscilações climáticas causam variações positivas e negativas de temperatura no país inteiro. O MDE (2006) afirma que a precipitação é mais escassa, ou seja, os períodos de chuva são mais curtos, mas às vezes as chuvas são densas, os períodos de seca são mais longos e generalizados e as inundações são mais frequentes. Esta situação resulta em uma redução muito significativa na produção agrícola, incluindo a pesca e a pecuária. Por outro lado, inundações, ciclones e inundações, são mais frequentes e causam enormes perdas materiais e humanas, com efeitos adversos na vida das famílias e da economia.

No entanto, o processo de impermeabilização do solo sob o efeito da erosão causa a maior parte da água da chuva nas áreas costeiras e ameaçada a vida nos ecossistemas terrestres e marinhos. Em algumas áreas, as inundações costeiras causam o colapso de muitas casas depois de ter invadido parcialmente ou completamente. Além disso, as águas residuais, com todos os tipos de resíduos trazidos pela água da chuva, poluem as zonas costeiras (MDE, 2006).

3.2. Vulnerabilidade socioeconômica do Haiti frente aos fenômenos climáticos. 
Para Ribeiro (2009), o conceito de vulnerabilidade é indissociável do conceito de risco. O autor relata que o conceito de risco está associado a vulnerabilidade, ou seja, que os processos eventualmente perigosos (sismos, inundações, incêndios, por exemplo) afetam, direta ou indiretamente, individual ou coletivamente, o ser humano, na sua saúde, nos seus bens ou nos modos de funcionamento das instituições em que se enquadram, na economia, na sociedade e na cultura. Para Cunha (2011), o conceito de vulnerabilidade deve estender-se também aos elementos mesológicos ou ambientais (água, ar, florestas, por exemplo), ou seja, a um conjunto de elementos que, apesar de exteriores ao ser humano, em muito contribuem para a sua qualidade de vida.

Souza (2013) entende a vulnerabilidade ambiental como a maior ou menor susceptibilidade de um ambiente a um impacto potencial provocado pelo uso antrópico, evidencia-se que a avaliação da capacidade de suporte da paisagem se constitui, na atualidade, uma necessidade para se evitar o comprometimento dos recursos naturais e a potencialização de processos morfogenéticos negativos.

Figueirêdo et al (2007) associam a vulnerabilidade ou fragilidade ambiental com a susceptibilidade de uma área em sofrer danos quando submetida a uma determinada ação. Desta maneira, o mapeamento tende a retratar uma espacialização, ou seja, um processo de formação e distribuição espacial, temporal e social diferenciado dos impactos ambientais. Assim, o mapeamento de impactos ambientais ou vulnerabilidade ambiental, certamente apresenta estreita relação com a espacialização diferencial das classes sociais na cidade, peculiar a cada momento de sua história social e política (COELHO, 2008).

Para Cetri (2018), devido à localização geográfica do Haiti, o país é particularmente propenso a desastres naturais como furacões, terremotos, inundações e secas. Assim, de acordo com o Índice Global de Risco Climático (CRC) 2017 da Germanwatch, o Haiti está classificado em $21^{\circ}$ lugar, além de ser um dos três países mais afetados por eventos climáticos no fragmento temporal de 1996 à 2015.

Em um contexto de vulnerabilidade econômica e tensões sociopolíticas, os sucessivos choques que afetaram o Haiti desde a década de 80 , tais como desastres naturais, epidemias e deslocamentos populacionais, combinados com problemas estruturais que limitam o acesso aos serviços básicos, agravaram significativamente a vulnerabilidade crônica da população, reduzindo sua resiliência (CETRI, 2018). Em janeiro de 2010, o Haiti foi atingido por um terremoto de magnitude 7.3 na escala de Richter que deixou cerca de 300.000 mortos e 1,5 milhão de pessoas desabrigadas. Neste contexto, a Organização das Nações Unidas para a Alimentação e a Agricultura tem buscado aprimorar as capacidades 
das instituições governamentais em prevenção e gestão de riscos e desastres bem como fortalecer os meios de subsistência de pessoas vulneráveis (FAO, 2019).

Estes perigos exacerbam a fragilidade dos recursos naturais já super-explorados, especialmente a floresta, embora saibamos que a cobertura vegetal ajuda a limitar as inundações causadas durante eventos extremos de chuva. Em relação à econômia, o país é particularmente sensível a choques exógenos. As perdas agrícolas podem testemunhar isso, sabendo que o país depende principalmente do setor primário. Por outro lado, devido a baixa renda per capita e o orçamento nacional o país não é capaz de realizar um plano de investimento a longo prazo, especialmente se esses investimentos estiverem expostos a riscos climáticos (MDE, PNUD, 2015). A figura 4 apresenta os impactos provocados pelos desastres naturais nos diferentes setores no Haiti.

\begin{tabular}{|l|c|l|l|l|l|l|c|}
\hline SETOR & Danos & Perdas & Total & $\begin{array}{l}\text { Parte } \\
\text { Pública }\end{array}$ & $\begin{array}{l}\text { Parte } \\
\text { Privada }\end{array}$ & $\begin{array}{l}\text { Balança de } \\
\text { pagamento } \\
\mathbf{s}\end{array}$ & Setor Fiscal \\
\hline Setores Sociais & $\mathbf{1 9 5 , 2 6}$ & $\mathbf{2 8 , 7 4}$ & $\mathbf{2 2 4 , 0 0}$ & $\mathbf{4 7 , 9 5}$ & $\mathbf{1 7 6 , 0 5}$ & $\mathbf{4 2 , 8 0}$ & $\mathbf{2 2 , 0 8}$ \\
\hline Educação & 27,91 & 1,14 & 29,05 & 14,60 & 14,45 & 3,28 & 1,13 \\
\hline Saúde & 9,94 & 5,20 & 15,14 & 14,86 & 0,28 & 7,11 & 2,54 \\
\hline Habitação & 157,41 & 22,40 & 179,81 & 18,49 & 161,32 & 32,41 & 18,42 \\
\hline Setores Produtivos & $\mathbf{1 0 8 , 5 5}$ & $\mathbf{3 2 0 , 6 8}$ & $\mathbf{4 2 9 , 2 3}$ & $\mathbf{5 , 0 0}$ & $\mathbf{4 2 4 , 2 3}$ & $\mathbf{3 8 1 , 2 3}$ & $\mathbf{1 , 9 7}$ \\
\hline Agricultura & 67,30 & 130,50 & 197,80 & 5,00 & 192,80 & 361,43 & N/a \\
\hline Indústria & 17,50 & 109,20 & 126,70 & 0,00 & 126,70 & $\mathrm{~N} / \mathrm{a}$ & $\mathrm{N} / \mathrm{a}$ \\
\hline Comércio & 18,10 & 61,30 & 79,40 & 0,00 & 79,40 & $\mathrm{~N} / \mathrm{a}$ & $\mathrm{N} / \mathrm{a}$ \\
\hline Turismo & 5,67 & 19,68 & 25,33 & 0,00 & 25,33 & 19,80 & 1,97 \\
\hline Infraestrutura & $\mathbf{8 7 , 7 8}$ & $\mathbf{7 1 , 4 4}$ & $\mathbf{1 5 9 , 2 2}$ & $\mathbf{7 6 , 2 4}$ & $\mathbf{8 2 , 9 8}$ & $\mathbf{5 5 , 8 2}$ & $\mathbf{1 2 , 3 2}$ \\
\hline Água e Saneamento & 13,16 & 6,35 & 19,51 & 11,83 & 7,68 & 5,96 & 7,10 \\
\hline Eletricidade & 5,62 & 2,08 & 7,70 & 7,70 & 0,00 & 0,76 & 2,30 \\
\hline Transporte & $\mathbf{6 9 , 0 0}$ & 62,40 & 131,40 & 56,10 & 75,30 & 49,10 & 2,30 \\
\hline Telecomunicação & 0,00 & 0,61 & 0,61 & 0,61 & 0,00 & nd & nd \\
\hline Setor transversal & $\mathbf{8 4 , 9 4}$ & $\mathbf{0 , 0 0}$ & $\mathbf{8 4 , 9 4}$ & $\mathbf{8 4 , 9 4}$ & $\mathbf{0 , 0 0}$ & $\mathbf{8 1 , 8 1}$ & $\mathbf{1 3 5 , 4 1}$ \\
\hline Meio Ambiente & 84,94 & 0,00 & 84,94 & 84,94 & 0,00 & $\mathrm{~N} / \mathrm{a}$ & 28,21 \\
\hline TOTAL & $\mathbf{4 7 6 , 5 3}$ & $\mathbf{4 2 0 , 8 6}$ & $\mathbf{8 9 7 , 3 9}$ & $\mathbf{2 1 4 , 1 3}$ & $\mathbf{6 8 3 , 2 6}$ & $\mathbf{5 6 1 , 6 6}$ & $\mathbf{1 7 1 , 7 8}$ \\
\hline
\end{tabular}

FIGURA 4. Efeito total do desastre por setores (em milhões de dólares).

Fonte: Adaptado do Relatório do Governo da República do Haiti (GRH), do Banco Mundial (BM), do Sistema das Nações Unidas (SNU), junto com a Comissão Europeia (CM), (2008). 
De acordo com MDE, PNUD (2015), a fragilidade do território haitiano pode ser compreendido pelas seguintes razões:

a) o país está situado na trajetória de grandes furacões tropicais. Entre 2004 e 2008, eventos extremos de larga escala se sucederam, custando mais de US \$ 7 bilhões de dólares de acordo com o Banco Mundial.

b) O Haiti apresenta um baixo nível de resiliência econômica, porque sua produção é amplamente baseada no setor agrícola (o setor primário fornece mais de um quarto do PIB). Essa sensibilidade é aumentada pela fragilidade dos ecossistemas, pelo baixo nível de saúde ou pelo crescimento acelerado de sua população.

c) Atualmente, a capacidade de adaptação do Haiti após um catástrofe é muito limitada devido ao seu baixo nível de renda. O país tem poucos fundos para investimentos públicos apropriados, embora tenha um apoio significativo da comunidade internacional.

De acordo com Banco Mundial (2019), em 2014, o PIB no Haiti era de US \$ 8.713 bilhões e a taxa de crescimento é estimada em 2,7\% em 2014. Em particular, 28\% da economia do Haiti é baseada no setor primário, $17 \%$ no setor secundário e $55 \%$ no setor terciário. É importante lembrar que a balança comercial deficitária, com uma tripla dependência das importações em relação ao orçamento, energia e alimentos, $50 \%$ do orçamento depende de ajuda externa, todos os hidrocarbonetos são importados e $60 \%$ das necessidades alimentares são supridas por importações.

O PNUD (2016) afirma que mais da metade da população do Haiti vive em áreas rurais, representando quase 6 milhões de pessoas e $85 \%$ dessa população rural pratica agricultura. O setor agrícola é, portanto, o maior fornecedor de empregos, aumentando ainda mais a vulnerabilidade da economia haitiana quando os desastres naturais afetam as plantações. Além das deficiências observadas na estrutura econômica do país, o Haiti sofre também de uma estrutura institucional frágil e pouco preparada para choques exógenos (CETRI, 2018). Apesar disso, o país se envolva na luta contra as mudanças climáticas em organismos internacionais.

\subsection{As principais consequências da seca no Haiti durante os últimos $\mathbf{3 0}$ anos}

O Haiti é considerado um dos países mais vulneráveis diante das adversidades do clima. Essa vulnerabilidade está parcialmente enraizada em uma exposição aos riscos climáticos, incluindo inundações, secas, furacões ou tempestades tropicais, e em parte em uma sensibilidade subjacente ao sistema socioecológico que recebe esses perigos. Entre 1990 e 2008, o Haiti foi o país do Caribe mais afetado por desastres naturais (3 secas, 1 epidemia, 22 inundações, 23 tempestades e furacões); os 53 bilhões de dólares em danos 
incorridos no país durante esse período representam $39 \%$ dos danos sofridos por toda a região (WEISSENBERGER, 2018).

Para o mesmo autor, em 2004, o furacão Jeanne matou mais de 3.000 pessoas. Os quatro furacões da temporada de furação de 2008 destruíram $80 \%$ da colheita e afetaram 800.000 pessoas. Em 2012, os furacões Isaac e Sandy, após uma seca, destruíram um terço das colheitas e deixaram a ameaça de desnutrição para 450.000 pessoas. O furacão Matthew 2016 devastou a parte sul do país, causando danos consideráveis às culturas e infraestrutura.

A Cooperazione Internationale (2018) afirma que o Haiti, por sua posição geográfica e sua constituição geológica, é um país muito exposto a desastres naturais. Os anos de 2014 e 2015 foram marcados por uma longa seca que afetou quase todo o país, afetando severamente os meios de subsistência e a segurança alimentar do país. As estimativas locais mostram que cerca de $30 \%$ das famílias têm dificuldade em realizar uma refeição por dia regularmente (FAO, 2019).

De acordo com o Ministère de l'Agriculture, des Ressources Naturelles et du Développement Rural ( MARND) 2014, como a economia do Haiti é baseada principalmente na agricultura, que emprega $60 \%$ da força de trabalho e contribui com cerca de $25 \%$ do produto interno bruto. O clima e a temperatura são fatores-chave para a resiliência e a produtividade agrícola. A produção agrícola consiste em culturas alimentares para a população local (especialmente milho) e culturas comerciais, como café, gerando renda com a exportação. A fragilidade da infraestrutura agrícola e das culturas diante dos riscos climáticos torna este setor altamente vulnerável a ciclones e inundações, que estão se tornando cada vez mais recorrentes no país. Embora a maioria dos haitianos dependa da agricultura para sua subsistência, o governo e os doadores até recentemente negligenciaram o setor agrícola em termos de investimento e inovação tecnológica (COOPI, 2018).

Para COOPI (2018) é cada vez mais difícil obter bons rendimentos agrícolas, devido as condições climáticas adversas, degradação do solo e perda de terras aráveis causadas por desmatamento, inundações, erosão, extração de madeira e baixa capacidade de agricultura de subsistência. O Haiti possui apenas $7.700 \mathrm{~km}^{2}$ de terra classificada como cultivável, com fortes declives e solos empobrecidos que se estendem por grande parte do território. No entanto, $11900 \mathrm{~km}^{2}$ (1,2 milhão de hectares) são realmente cultivados, o que significa que uma quantidade significativa de terra que não é adequada para a agricultura está atualmente sendo explorada. As parcelas das planícies cobrem cerca de 550.000 hectares e o potencial de irrigação chega a 135.000 a 150.000 hectares. Entretanto, apenas 
90.000 hectares se beneficiam atualmente de um sistema de irrigação, dos quais 80.000 ha são realmente irrigados (WEISSENBERGER, 2018).

O ciclo de secas, tempestades e inundações tem um forte impacto negativo sobre a agricultura no Haiti, e a irregularidade do período chuvoso está impedindo qualquer planejamento do calendário agrícola pelos agricultores. O mês de julho coincide com a colheita da maioria das culturas semeadas entre março e abril em todo o país. Milho, feijão de montanha, ervilha desconhecida e tubérculos são as principais culturas colhidas durante esse período. Este é um dos meses do ano em que as categorias pobres e muito pobres se alimentam de sua própria produção, com a possibilidade de vender parte dela. No entanto, devido ao período de seca dos anos de 2014 e 2015, em muitas partes do país, as colheitas estão abaixo da média (CNSA/FEWSNET, 2015). A figura 5 exemplifica as diferentes zonas de segurança alimentar no Haiti em 2015 (cada cor apresenta um tipo de produção agrícola).

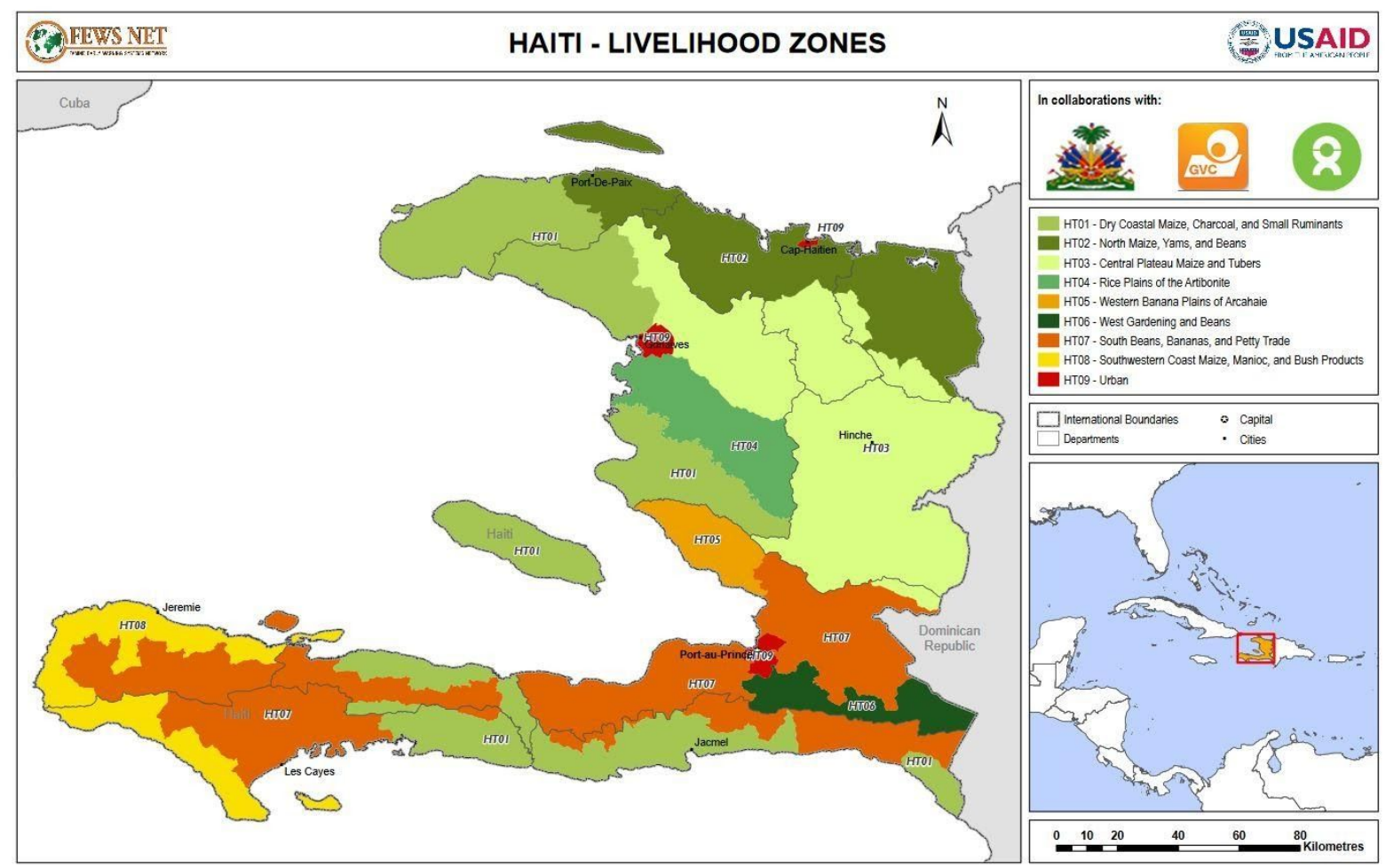

FIGURA 5: Mapa de segurança alimentar no território haitiano em 2017. | Fonte: CNSA/FEWSNET, 2015

De acordo com a CNSA/FEWSNET (2015), a estação chuvosa, que geralmente se estende de março / abril a junho, foi mais irregular durante este período (2014 e 2015), iniciou-se mais de 40 dias atrasado no nordeste, Artibonite e partes do sudeste. O mês de maio, tipicamente um dos mais chuvosos, apresentou déficits pluviométricos entre 100 e 200 $\mathrm{mm}$ na maior parte do país. Registrou-se também um déficit de 300 milímetros em partes nos departamentos de Sud e Grand Anse, que geralmente têm mais de $500 \mathrm{~mm}$ de precipitação 
entre maio e julho. De acordo com os resultados de sensoriamento remoto da Tropical Rainfall Monitoring Mission (TRMM), o Plateau Central e o Artibonitite receberam chuvas entre 80 e 120\% entre 27 de março a 24 de junho (CNSA/FEWSNET, 2015).

Os índices de vegetação e os requisitos de água no solo, fornecidos a partir de imagens do sensor MODIS (satélites AQUA e TERRA), refletem condições de stresse hídrico desfavorável ao bom desenvolvimento das culturas ao longo da estação. Para o Ministério da Agricultura, dos Recursos Naturais e do Desenvolvimento Rural (MARNDR, 2014), essa queda geral nas chuvas está relacionada ao fenômeno El Niño que vem desenvolvendo desde o mês de março e é caracterizada por chuvas sazonais em abaixo da média. Observa-se que não apenas no Haiti, mas em muitas áreas do Caribe e os departamentos do Noroeste, Sudeste, Nordeste, Península Sul, parte do Departamento de Oeste e Norte, são os mais afetados pela seca.

Assim sendo, as perdas registradas nas culturas de milho e feijão no departamento de sudeste foram aproximadamente de $100 \%$. A situação não é muito diferente no departamento sul, exceto nas áreas irrigadas (CNSA/FEWSNET, 2015). O Catholic Relief Services (CRS) estima que nesta área ocorram perdas em mais de $50 \%$ das áreas irrigadas e são ainda mais altos em áreas de sequeiro, onde excedem $80 \%$. Por outro lado, no Plateau Central, os campos estabelecidos entre o final de maio e o início de junho, sofrem com o stresse hídrico, o que causa a murcha das plantações de milho em áreas com solos rasos. É o caso da ervilha desconhecida (nome de um tipo de feijão no Haiti) em Thomassique e em algumas localidades em Hinche e Maïssade, bem como no norte. Mangas fora de estação também estão sendo colhidas no norte do plateau central e em muitas partes do país, como Tiburon (MARNDR, 2014). A figura 6 apresenta a anomalia do NDVI (Índice de Vegetação da diferença Normalizada) calculado para o país entre o período de 21 a 30 de junho de 2015, em relação a media dos anos de 2001 a 2010, ilustrando o comportamento das plantas em relação a seca. É possível observar que a vegetação nos dez (10) departamentos do país foram afetados pela seca apresentando anomalias negativas de NDVI. 


\section{eMODIS 250m NDVI Anomaly}

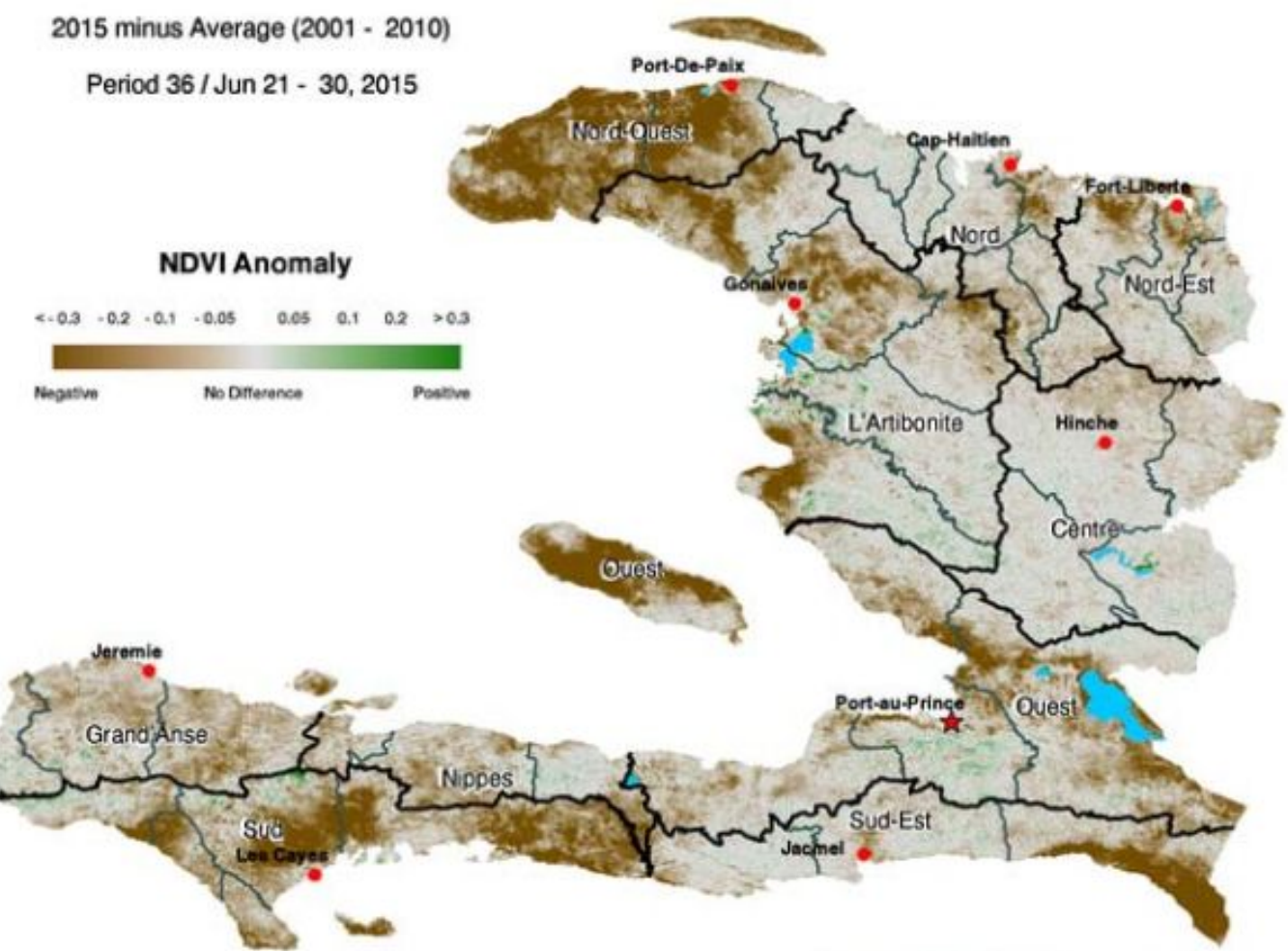

FIGURA 6: Anomalia no índice de vegetação (NDVI) em 2015 no Haitiana. | Fonte: CNSA/FEWSNET, 2015

Como consequênciais imediatas da seca de 2015, durante os meses de junho e julho, os preços de alimentos básicos, como feijão e milho moído, geralmente iconheceram declínios significativos, alimentados pelas colheitas da primavera. No entanto, para esta mesma temporada, observou-se uma tendência contrária (ACF, 2016). A ACF aponta que preços dos alimentos básicos subiram, em alguns casos superando de maneira considerável os da média quinquenal e de 2014 no mesmo período. Essa tendência refletiu o fraco desempenho da produção agrícola da primavera, conhecida como a mais importante do país. A farinha de milho registrou aumentos de $11 \%$ e $20 \%$, respectivamente, nos mercados locais de Porto Príncipe e Jeremie em comparação a maio de 2015. Ao longo do deste ano, o preço do milho aumentou variando de $5 \%$ no mercado de Cap-Haitien (norte do país) a $108 \%$ no mercado de Jérémie (sudoeste do país) (CNSA/FEWSNET, 2015).

A avaliação realizada pela Organização das Nações Unidades (ONU, 2015) indicou que a colheita da primavera de 2015 foi muito abaixo da média esperada no Haiti, com quase $3 / 4$ dos agricultores do país reportando perdas que chegaram a $80 \%$ da sua produção. Para a colheita de 2016, reparou-se que $65 \%$ dos agricultores haitianos não tinham sequer sementes para plantar. A escassez de alimentos locais já causou a elevação média de preços de quase $60 \%$. 
Por outro lado, a (ONU, 2015) apontou que 3,6 milhões de haitianos enfrentam insegurança alimentar, sendo que 1,5 milhão está sendo severamente afetado na sua alimentação cotidiana. Assim, a ONU anunciou uma operação de emergência para atender um milhão de pessoas no Haiti com o intuito destinar transferência de recursos para quase 700 mil pessoas, com o propósito de facilitar a aquisição de comida e fortalecer a economia local. A agência de ajuda alimentar das Nações Unidas por sua vez anunciou uma ajuda humanitária de 1,6 milhão de pessoas atingidas por secas exacerbadas pelo fenômeno 'El Niño' na Guatemala, Honduras, El Salvador e Haiti, apoiando a capacitação de resiliência contra futuros choques climáticos ( NAÇÕES UNIDAS BRASIL, 2016).

De acordo com FAO (2019), em 2018, a temporada agrícola da primavera foi afetada pela seca relacionada ao fenômeno El Niño em várias áreas do país, incluindo os departamentos de Centro, Grand'Anse, Norte, Nordeste, Oeste, Sul e Sudeste. Isso resultou mais uma vez em uma produção reduzida das principais culturas de feijão, milho e sorgo, afetando severamente a segurança alimentar e a renda dos haitianos cujos meios de subsistência vem da agricultura. Consequentemente, o poder de compra das famílias também foi afetado pelo aumento dos preços dos alimentos básicos, o que prejudica a capacidade das famílias vulneráveis de acessar o mercado de alimentos e levando à adoção de mecanismos negativos.

A pesca é outra atividade de subsistência praticada no Haiti. De acordo com FAO (2019) apenas um terço do peixe consumido no Haiti é fornecido pelo setor de pesca marinha local. A pesquisa aponta que essa lacuna entre o consumo e a produção local de pescado é resultado da baixa produtividade do setor, o que pode ser explicado por diversos fatores, dentre elas, a plataforma continental do Haiti é pequena em área (aproximadamente 5.000 $\mathrm{km}^{2}$ ), e com uma extensão que na maior parte não excede um quilômetro da linha de base costeira.

A Ação Contra a Fome (ACF, 2013) afirma que a pesca nas áreas costeiras também é afetada pela acidificação do oceano (devido às concentrações de $\mathrm{CO} 2$ no ar). Uma estimativa dos custos dos impactos das mudanças climáticas no Haiti mostrou que o custo da inação (US \$1,8 bilhão) foi muito superior ao necessário para adaptar os meios de subsistência e a infraestrutura (261, US \$ 48 milhões).

Por outro lado, a degradação das bacias hidrográficas e o declínio da produtividade agrícola estão levando muitos agricultores a ocupar as zonas costeiras na esperança de encontrar melhores condições de vida. Contudo, a agricultura e outras atividades da bacia hidrográfica estão causando aumento da erosão, que transporta sedimentos para as águas costeiras, afetando a qualidade da água, particularmente os corais, que estes privam de luz. 
Esta atividade tem como consequência imediata a redução das receitas da pesca e forçar os pescadores a intensificar suas atividades agrícolas, de forma inadequada nas zonas costeiras que pode aumentar a vulnerabilidade ambiental, especialmente se os impactos das mudanças climáticas sobre ecossistemas costeiros são levados em consideração .

\section{Conclusão}

Dentre as medidas que visam melhorar este cenário, o investimento em pequenas empresas agrícolas haitianas e no setor agrícola em geral é essencial para melhorar a resiliência climática. Portanto, é importante promover um modelo agrícola adaptado às realidades haitianas e que garanta a segurança alimentar do país. As políticas de áreas protegidas devem enfatizar o envolvimento da população local na delimitação e proteção dessas áreas, o que também pode criar oportunidades de emprego no eco-turismo. Os planos estratégicos devem incluir outras atividades geradoras de renda (indústria, turismo, serviços etc.) para reduzir a pressão sobre a agricultura. Esses esforços devem ser apoiados por pesquisas destinadas a uma agricultura mais resiliente, apoiadas por estruturas de treinamento mais eficientes e apoiadas por um acesso mais fácil ao financiamento para pequenos produtores.

Uma política focada na resiliência será, portanto, importante não apenas para mitigar o impacto de eventos adversos, mas também para fortalecer o sistema socioeconômico subjacente, o que obviamente implica muitas linhas de ação que visam a proteção dos ecossistemas, formentando as capacidades agrícolas, mantendo a integridade do solo, o acesso à água e outros recursos, a estrutura territorial para o desenvolvimento, construindo padrões, governando e participação pública, educação e sensibilização.

Por fim, seria importante um projeto de captação da água de chuva a curto prazo como alternativa viável que em associação com outras políticas públicas, contribuirá para o desenvolvimento sustentável da população haitiana, entre as formas de mitigar os efeitos da seca. Por outro lado, a utilização da água subterrânea, assim como construção de cisternas pode ser outra alternativa com melhor relação custo e benefício. A aplicação destas medidas podem garantir a curto e longo prazo um território haitiano com melhor qualidade de vida. 
ACF- Action Contre la Faim. "Diagostic de la prise em compte du changement climatique dans les politiques liées à la sécurité alimentaire et la nutition em Haiti”. Setembre 2016. ACF- Action Contre la Faim. "Haiti Humanitarian Action Plan". 2013.

AGÊNCIA BRASIL. Seca prolongada causa grave crise alimentar no Haiti, adverte ONU. Brasília, 2014.

ALTER PRESSE. "Haiti: la sécheresse cause de sériuex ravages dans les plantations à Belladère". Mai, 2015.

BM- Banque Mondial. “Haiti est pays extrêmement vulvérable face aux catastrophes naturelles, auquelles son exposés plus de $90 \%$ de as population. Le sud de l'île a été ravagé par l'ouragan Matthew le 4 octobre 2016, la catastrophe la plus dévastatrice depuis le séisme de 2010". Octobre, 2019.

CEPAL- Comisión Económica para América Latina y el Caribe. "Panorama multidimensional del desarrollo urbano en América Latina y el Caribe”. Documentos de proyectos. Santiago, junho de 2010.

CETRI. "Le cercle vicieux de la vulnérabilidade". Fevrier, 2018.

Climate-Data. ORG, disponível em, https://fr.climate-data.org/amerique-du-nord/haiti/departement-de-I-ouest/arcahaie-29873/\#cli mate-graph. Acessado em 12 de Julho de 2019.

CNSA/FEWSNET. "Low production levels to cause a deterioration of food security through March". October 2014 to March 2015.

COELHO, A. L. N. Uso de dados SRTM como ferramenta de apoio ao mapeamento geomorfológico de bacia de médio-grande porte. Revista Geografia Acadêmica, v.2, n.2, p.138-153. 2008.

COOPI- Cooperazione Internazionale. "Haiti: prévenir la sécheresse pour répondre à l'insécurité alimentaire”. Décembre, 2018.

CUNHA, C. M. L. A cartografia geomorfológica em áreas litorâneas. Tese apresentada ao Instituto de Geociências e Ciências Exatas do Campus de Rio Claro, Universidade Estadual Paulista Julio de Mesquita Filho (Livre-docência em Geomorfologia). Rio Claro. 2011.

FAO- Organização das Nações Unidas para a Alimentação e a Agricultura. "Haiti Emergency Response Plan”. March-May, 2019.

FIGUEIRÊDO, Maria Clea Brito. et al. Avaliação da Vulnerabilidade Ambiental de Reservatórios à Eutrofização. Revista Engenharia Sanitária e Ambiental, Rio de Janeiro, v. 12, n. 4, p. 399-409, out. 2007. 
Gouvernement de la République d'Haiti (GRH), Banque Mondial (BM), Système des Nations-Unies (SNU), Commission Européenne (CM). (Novembre 2008) "Rapport d'evaluation des besions après désastre Cyclone Flay, Gustav, Hanna et Ike".

IHSI- Institut Haitien de Statistique et d'Informatique. (Mars 2002). “Unité de decentralisation et des collectivités territoriales".

JEUNE, W. "Solos e ambientes no Haiti ocidental: Gênese, classificação e mapeamento". Tese apresentada à Universidade Federal de Viçosa, como parte das exigências do programa de Pós-Graduação. Minas Gerais, 2015.

MARCONI, M \& LAKATOS E. M. (2001). "Fondamentos de metodologia Cientifica". Atlas, São Paulo.

MARNDR- Ministère de l'Agriculture, des Ressources Naturelles et du Développement Rural (1962). Loi du 24 Mai 1962, No VIII (Des Forêts) Extraits du Code Rural, 2014.

MDE- Ministère de l'Environnement. "Plan d'Action National d'Adaptation (PANA)". Octobre, 2006.

MDE, MNUD. "Estimation des coûts des impact du changement climatique em Haiti". Projet de renforcement des capacités adaptatives des communautés côtières d'Haiti aux changement climatiques ( GEF ID n³733/PIMS ID n³971). Septembre 2015.

Rapport de cherche OXFAM" Adaptationaux changements climatiques" le cas d'Haiti. Mars, 2014.

CNSA / FEWSNET. "Haiti Perspective sur la sécurité alimentaire". La sécheresse persistante maintient la catégorie des très pauvres em Crise dans certaines zones. Juillet à décembre 2015.

LE NOUVELLISTE. "Conflits et sécheresse exacerbent les besions alimentaires, Haiti sur la liste". Port-Au-Prince, Juin, 2016.

MAZZER A.M. Proposta Metodológica de Análise de Vulnerabilidade da Orla Marítima à ErosãoCosteira: Aplicação na Costa Sudeste da llha de Santa Catarina, Florianópolis-SC, Brasil. 2007. Tese de Doutorado (Programa de Pós Graduação em Geociências) Universidade Federal do Rio Grande do Sul.

NAÇÕES UNIDAS BRASIL. Fome aumenta na América Central e Haiti em meio a seca agrava por El Niño. Abril de 2016.

ONU- Organisations des Nations Unies. (Septembre, 2010). "Haiti dévasté apres le passage des cyclones Ike e Hanna, Flay e Gustave".

OXFAM. "ONG Oxfam no olho do furação após escâdalo sexual no Haiti. Fevereiro, 2018. 
PNUE- Programme des Nations Unies pour l'Environnement. "Haiti, chaines d'approvisionnement du charbon de bois et du bois de jeu dans le département du Sud". Septembre, 2016.

PNUE- Programme des Nations Unies pour l'Environnement. "Saison cyclonique 2010: avec le soutien de ses partenaires, la DPC prépare les brigadiers (ères) volontaires". Août, 2019.

RIBEIRO, $H$. et al. Coleta seletiva com inclusão social: cooperativismo e sustentabilidade. São Paulo: Annablume, 2009.

SOUZA, S. O. Proposta de Zoneamento Geoambiental Como Subsídio ao Planejamento do Uso e da Ocupação da Região Costa das Baleias (BAHIA). Tese de Doutorado, Instituto de Geociências-Universidade Estadual de Campinas, 2013.

VILLA, F.; McLEOD, $H$. Environmental vulnerability indicators for environmental planning and decision-making: guidelines and applications. Environmental management, v. 29, n. 3, p. 335-348, 2002.

WEISSENBERGER, S. Haiti: vulnérabilité, résilience et changements climatiques. Haïti Perspectives, vol. 6. no ${ }^{3}$. Été, 2018.

WOODRING, W.P., J.S. BROWN, AND W.S. BURBANK. Geology of the Republic of Haiti. Department of Public Works, Baltimore, Maryland: Lord Baltimore Press. 1924. 631p. 